\title{
Arabic Version of Hearing Impairment of Teachers Job Satisfaction: Validation of Measurement Instrument Using Partial Least Square
}

\author{
Sulaiman M. Alshutwi, Aznan Che Ahmad*, Lay Wah Lee \\ School of Educational Studies, Universiti Sains Malaysia Penang, 11800, Malaysia
}

Received September 26, 2020; Revised November 24, 2020; Accepted December 6, 2020

\section{Cite This Paper in the following Citation Styles}

(a): [1] Sulaiman M. Alshutwi, Aznan Che Ahmad, Lay Wah LEE , "Arabic Version of Hearing Impairment of Teachers Job Satisfaction: Validation of Measurement Instrument Using Partial Least Square," Universal Journal of Educational Research, Vol. 8, No. 12A, pp. 7957-7973, 2020. DOI: 10.13189/ujer.2020.082584.

(b): Sulaiman M. Alshutwi, Aznan Che Ahmad, Lay Wah LEE (2020). Arabic Version of Hearing Impairment of Teachers Job Satisfaction: Validation of Measurement Instrument Using Partial Least Square. Universal Journal of Educational Research, 8(12A), 7957-7973. DOI: 10.13189/ujer.2020.082584.

Copyright $\subseteq 2020$ by authors, all rights reserved. Authors agree that this article remains permanently open access under the terms of the Creative Commons Attribution License 4.0 International License

\begin{abstract}
Hearing impairment of teachers' job satisfaction is an aspect that deals with affective. Earlier studies had reported that it could stimulate attitude and efficiency of teachers towards their job. Meanwhile, most of the instruments available to measure this construct were validated using outdated psychometric methods. This study therefore adopted a survey research type of non-experimental design to adapt Teachers Job Satisfaction for Hearing Impairment Scale (TJSHIS). The sample consisted of two hundred and nine (209) teachers of hearing impairment from twenty schools randomly selected from co-educational public schools in Saudi Arabia. Data were analysed using, Parallel Analysis (PA), Exploratory Factor Analysis (EFA), Measurement model and Confirmatory Factor Analysis (CFA). The results showed that the scale was reliable and had construct validity. Also, the scale was reduced from sixty-five (65) to forty-four (44) items across three (3) factors with final compliance indices chi-square: $=2020.196, \mathrm{p}=0.31$, RMSEA $=0.05, \mathrm{TLI}=0.95, \mathrm{SRMR}=0.015, \mathrm{CFI}=0.97$, $\mathrm{AIC}=27944.582$ and $\mathrm{BIC}=28395.798$. The composite reliability index of the three (3) factors of TJSHIS was 0.93, while the reliability index of each of the subscales of the TJSHIS ranged from 0.91 to 0.95 . The author encourages researchers to use the scale for measuring hearing impairment teachers job satisfaction in Arab countries.
\end{abstract}

Keywords Job Satisfaction, Hearing Impairment, Partial Least Square- Structural Equation Modeling

\section{Introduction}

In this 21st century, job satisfaction is one of the concepts that cannot be overemphasized. For the most part, it has been one of the foremost critical components, broadly investigated over the world and more than twelve thousand studies were published within the field of special education, which proves the significance of this concept [1]. Thus, job satisfaction can be portrayed as the enthusiastic conduct that's created as a result of a person's subjective assessment towards his work and work environment. Individuals work to gain their livings and they may have certain states of mind towards their occupations. When they like their occupations and create a positive state of mind, it is called job satisfaction and if otherwise is called dissatisfaction [2]. Teachers Job satisfaction is exceptionally basic. Hence, all organizations and institutions wish their workers to be fulfilled with their occupations. In this setting, an investigation has shown that job satisfaction influences participation, the salary of the work environment, work performance, conduct and demeanour against working environment [3]. In another study, it was uncovered that job satisfaction is at the beat of the need list of any institution which their goals are to retain uncommonly and be recognized competent staff [4]. Particularly, within the 
field of special education, in recent years, increasingly individuals around the world are in need of procuring a better level of competence in teaching students who are deaf or hard of hearing because it is getting to be more well known within the world. As such, job satisfaction takes a central position among special education instructors particularly those that deal with deaf or hearing impairment.

Hence, initiatives ought to be taken to move forward special education, particularly in Arab countries. Hearing impairment teachers play a critical role in execution of special education; in any case, the steady loss or burn-out rate for teachers that deal with deaf or difficult of hearing students is greatly high compared to most other callings due to lack of variables such as appreciation, parental back, and open bolster, as well as overwhelming workload on paperwork. They have to be collaborated with regular classroom instructors, information collection on prove of development of students and the differing qualities of student's needs [5]. Additionally, [6] commented that the works done by the special education instructors can be candidly requesting and physically depleting. Numerous special education instructors are beneath significant stretch due to overwhelming workloads and administrative assignments. They must deliver a considerable amount of paperwork recording each student's advance and work beneath the risk of the case against the school or locale by guardians in case correct methods are not followed or in case the guardians feel that their child isn't getting a satisfactory education. Based on this literature, numerous variables impact the job satisfaction of hearing impairment teachers such as advancements, classroom environment, pay, school environment, personal growth etc. Hence, improving their job satisfaction can act as one significant step in moving forward to the special education framework in schools in Arab nations. More imperatively, to the information of the researcher, no studies have been conducted on developing and validating hearing impairment of teachers' job satisfaction scale in any of the Arab countries. In this manner, the present study set out to isolate distinctive factors that would improve the hearing impairment of teachers' job satisfaction in Arab nations through validated and reliable scale items.

More so, scrutiny of literature on job satisfaction has appeared that's one of the foremost broadly investigated concepts in organizational Psychology [7][8]. Besides, various studies on motivation hypotheses have confirmed the fundamental role of job satisfaction. Theories on job satisfaction such as Bandura's (1977) Social Learning Theory have endeavoured to conceptualize job satisfaction and its impact. This kind of expound research has of late occasioned job satisfaction being connected to efficiency, inspiration, absenteeism/tardiness, mishaps, mental/physical wellbeing, and general life fulfillment. Actually, as remarked by [7][9], a common theory inside the literature has been that, to a degree, the passionate state of an individual is influenced by interactions inside their work environment. Moreover, a few aspects associated with job satisfaction as laid out in research include payment for the work, work obligations, task variety, openings for advancement, the work itself, and co-workers. Moreover, other basic components incorporate general well-being, push at work, control at work, the home-work interface, and working conditions. A few researchers partition the factors as environmental and individual components [10] [11]; these components are the job satisfaction of instructors straightforwardly or indirectly. Be that as it may, [12][13] listed out a range variable in connection to job satisfaction such as independence in job, task significance, supervision in work, school rules and work conditions, knowledge and skills in job, feedback in job, patents' back, enhancement openings in work, school community relationship in job, payment for work, different aptitudes for work, other teachers' relationship in job, over workload and work push. These variables can be considered as a few of components that can influence hearing impairment of teachers' job satisfaction.

More importantly, while the noteworthy role of teachers' work for student results is broadly recognized, the address of whether teachers are satisfied with their working environment is regularly ignored [14][15]. In any case, teacher job satisfaction has numerous important and far-reaching suggestions. To begin with, it contributes to teacher well-being as fulfilled teachers are less vulnerable to stretch and burnout [16]. In addition, there's proof that students of teachers who are please with their work also feel better [17][18]. Besides, fulfilled teachers offer higher directions quality and way better learning bolster for their students [19]. Finally, comfortable teachers demonstrate more grounded job commitment and dedication. [20] proposed that job satisfaction is meant as the emotions about the job which persuades a person for the achievement of assignments, tasks and stays competent about the job. [20] remarks that there are two levels of job satisfaction. One is related to feelings which are related to the job and the other is subjective work satisfaction. Subjective fulfilment is the subjective feelings related with a few portions of their job, etc. work hours, pay, remittances or other focal points. Recently, several research studies have examined job satisfaction of special education instructors. These incorporate, [21] found that instructors experienced a normal level of job satisfaction and [4] found that the level of job fulfillment helps to improve teachers' work viability, and also highlighted the need of giving a suitable work environment to energize the teachers who work with students with inability.

There are numerous studies carried out on the job satisfaction of teachers in Saudi Arabia. A very larger percentage of them focused on teachers in general schools and examples of such studies can be linked to the following researchers, they are: (Alomari 1992; Newby 1999; Alonazi 2002; James 2004; Yaseen1990; Alsaraf et al. 1994; Alaraimi 1998; Tieam 1999; Alroyali 2001; 
Alagbari 2003; Almutairi 2005). However, in the educational field of Arabic context, most researchers had designed their scales in the time past which were characterized by the absence of robust psychometric properties of those items of the scale. In addition to that, this cast scepticism on their applicability since the outcome in the area of special education is different from those in the field of general education. Moreover, these doubts will increase in the case of using these instruments in the special education context. Consequently, researcher extensive reviewed of literature in relation to hearing impairment of teachers' job satisfaction depicts that there is need to develop and validate measurement instrument that can be used uniformly to measure job satisfaction of teachers of deaf or hard of hearing across the Arab countries. The research questions advanced for this study were in threefold: These are: (a) How many factors are underlying Hearing Impairment of Teachers Job Satisfaction Scale? (b) What is the convergent and discriminant validity of the scale? (c) Do the fit indices explain the model of Hearing Impairment of Teachers Job Satisfaction Scale?

\section{Methodology}

The research questions advanced for this study were in threefold: These are: (a) How many factors underlying Hearing Impairment of Teachers Job Satisfaction Scale? (b) What is the convergent and discriminant validity of the scale? (c) Does the fit indices explain the model of Hearing Impairment of Teachers Job Satisfaction Scale? Survey research type of non-experimental design was used.

\subsection{Participants}

The population for the study consisted of teachers of deaf or hard of hearing in special schools of the deaf and public schools in Saudi Arabia. The Sampling technique was carried out in two stages and two sets of samples were obtained. In each stage, multi-stage sampling procedure was used. First, Saudi Arabia has thirteen educational districts; four (4) districts were selected through simple random sampling namely; district 1 , district 2, district 3 and district 4 respectively. Next, selection of the public schools was drawn randomly, in which four (4) schools were selected from each educational district making sixteen (16) schools in all for the sample. In each centre, purposive sampling technique was used to select thirteen (13) teachers from each district for equal representation, bringing the total number of teachers that participated in the study to two hundred and nine (209).In stage one (n1), the initial item pool of HITJSS was administered while in stage two (n2), the extracted items were re-administered to a larger population. Consequently, the sample with $\mathrm{n} 1=100$ was used to conduct parallel analysis (PA) and exploratory factor analysis (EFA) while the sample with $\mathrm{n} 2=209$ was used to validate sample for the confirmatory factor analysis (CFA). Among the 209 sampled participants for the two stages, 68 (32.5\%) were men and 141 (67.5\%) were women.

\subsection{Measures}

The researchers adopted the instrument developed by Luckner \& Dorn , 2017 [22] called Hearing Impairment of Teachers Job Satisfaction Scale (HITJSS). The scale consisted of drafted seventy (70) items and after reviewed by the experts in scale development, with content validity index (CVI) of 0.79 , the scale was reduced to sixty-five (65) items with 4-point Likert scale, $4=$ very satisfied, $3=$ satisfied, $2=$ dissatisfied, $1=$ very dissatisfied. Also, Omega reliability was very high for the construct and sub-constructs. The coefficient for the original scale was 0.930 , and the first factor of scale was 0.956, the second factor was 0.919, and the third factor was 0.921 respectively. Scores on negative items were reversed before the analysis. Data obtained were analysed using parallel Analysis (PA), Exploratory Factor Analysis (EFA), Measurement model and Confirmatory Factor Analysis (CFA).

\subsection{Procedures}

The following steps were as follows.

1) The translation of the HITJSS was kindly approved by the author.

2) The selected questionnaire was originally developed in English by (Luckner \& Dorn, 2017). However, since the main language in Saudi Arabia is Arabic, therefore, for the convenience of the respondents, it was essential to translate the questionnaire from English to Arabic. The translation was done using the back-translation procedure. Back-translation is the most popular way to ensure reliability and validity of the questionnaire (Sekaran, 2003). The whole questionnaire was first translated into Arabic by one bi-linguist, and the translation was reviewed by academic experts in the educational field at Universities in Saudi Arabia. Later, a different bi-linguist translated the Arabic version back to English. Forward and backward translation was performed taking into consideration vocabularies, concepts to ensure the accuracy of the translation process.

3) A pilot study of this study was done to test the reliability of the Arabic version of the scale: the expert team was asked to evaluate each statement (instructions, items, and choices) of the tool for clarity using a dichotomous scale (yes/no). If the answer was 
no, they were asked to give their suggestions to improve each item.

\subsection{Data Analysis}

Data analysis was conducted to determine the reliability and structural validity of HITJSS. Parallel analysis, exploratory factor analysis, measurement model and confirmatory factor analysis were performed to ascertain the structural validity of the scale items. R programming language version 3.4.6 was used for parallel analysis and exploratory factor analysis to see the interaction between the scale items and their factors. Also, principal axis factoring extraction method with orthogonal rotation was used to establish the factor structure of the scale, and scree plot analysis was further conducted to verify the actual number of factors embedded in the scale. Also, SmartPLS software version 3.2.9 was used to assess the measurement model (that is convergent and discriminant validity) of the instrument while Mplus version 7.1 software program was used to establish confirmatory factor analysis, and substantiate the tenability of the factor structure that was built through exploratory factor analysis. However, in order to assess the stability of this model, values of chi-square $(\chi 2 \geq 1)$, Probability level ( $p \geq 0.05)$, degree of freedom ( $\mathrm{df} \geq 1$ ), Tucker-Lewis index (TLI $\geq$ 0.95), the goodness of fit index (GFI < 0.95), comparative fit index (CFI $\geq 0.90)$, Root mean square residual (SRMR $\leq 0.08$ ) and root-mean-square error of approximation (RMSEA $\leq$ 0.06) were determined [23]. Consequently, forty-four (44) items conclusively formed HITJSS. Furthermore, internal consistency of the scale and subscales was established using composite reliability coefficient.

\section{Results and Discussion}

\section{(a) How many factors underlying Hearing Impairment of Teachers Job Satisfaction Scale?}

To determine the number of factors that are extracted from the scale, participants' responses to the items were subjected to parallel analysis test using psych package implemented in $\mathrm{R}$ programming language software. Parallel Analysis (PA) is a method based on the generation of random variables, for the determination of factors that underlies a test. Thus, Ledesma, R.D. \& Valero-Mora (2007) remarks that a factor is retained if its eigenvalue is found greater than the mean of the eigenvalues from its randomly generated counterpart. The extracted factor(s) provide evidence for evaluating the number of factors underlying the scale. Table 1 presents the result of parallel analysis test showing number of factors underlie the HITJSS;

Table 1. Parallel Analysis Test Showing Number of Factors of the Scale

\begin{tabular}{|c|c|c|c|c|c|}
\hline Component & Real Eigenvalues & Simulated Eigenvalues & Component & Real Eigenvalues & Simulated Eigenvalues \\
\hline 1 & 19.27 & 1.07 & 34 & -0.36 & -0.20 \\
\hline 2 & 8.17 & 1.20 & 35 & -0.37 & -0.23 \\
\hline 3 & 3.37 & 1.17 & 36 & -0.38 & -0.25 \\
\hline 4 & 1.70 & 1.10 & 37 & -0.39 & -0.27 \\
\hline 5 & 1.43 & 1.02 & 38 & -0.42 & -0.30 \\
\hline 6 & 1.15 & 0.93 & 39 & -0.43 & -0.33 \\
\hline 7 & 0.86 & 0.88 & 40 & -0.44 & -0.35 \\
\hline 8 & 0.79 & 0.81 & 41 & -0.47 & -0.38 \\
\hline 9 & 0.74 & 0.76 & 42 & -0.49 & -0.40 \\
\hline 10 & 0.69 & 0.70 & 43 & -0.51 & -0.43 \\
\hline 11 & 0.56 & 0.65 & 44 & -0.54 & -0.45 \\
\hline 12 & 0.54 & 0.59 & 45 & -0.56 & -0.47 \\
\hline 13 & 0.44 & 0.54 & 46 & -0.59 & -0.49 \\
\hline 14 & 0.34 & 0.50 & 47 & -0.59 & -0.52 \\
\hline 15 & 0.23 & 0.46 & 48 & -0.60 & -0.54 \\
\hline 16 & 0.23 & 0.41 & 49 & -0.61 & -0.56 \\
\hline 17 & 0.17 & 0.38 & 50 & -0.62 & -0.58 \\
\hline 18 & 0.12 & 0.34 & 51 & -0.64 & -0.60 \\
\hline 19 & 0.09 & 0.31 & 52 & -0.65 & -0.63 \\
\hline 20 & 0.04 & 0.26 & 53 & -0.67 & -0.65 \\
\hline 21 & -0.01 & 0.22 & 54 & -0.68 & -0.67 \\
\hline
\end{tabular}


Table 1 continued

\begin{tabular}{|l|l|l|l|l|l|}
\hline 22 & -0.04 & 0.19 & 55 & -0.69 & -0.68 \\
\hline 23 & -0.06 & 0.15 & 56 & -0.70 & -0.71 \\
\hline 24 & -0.14 & 0.11 & 57 & -0.72 & -0.73 \\
\hline 25 & -0.15 & 0.07 & 58 & -0.73 & -0.74 \\
\hline 26 & -0.18 & 0.04 & 59 & -0.74 & 0.57 \\
\hline 27 & -0.22 & 0.02 & 60 & -0.76 & 1.47 \\
\hline 28 & -0.23 & -0.02 & 61 & -0.77 & 1.45 \\
\hline 29 & -0.24 & -0.05 & 62 & -0.78 & 0.38 \\
\hline 30 & -0.25 & -0.08 & 63 & -0.81 & 1.01 \\
\hline 31 & -0.31 & -0.11 & 64 & -0.81 & 1.04 \\
\hline 32 & -0.32 & -0.14 & 65 & -0.82 & 0.00 \\
\hline 33 & -0.33 & -0.18 & & & \\
\hline
\end{tabular}

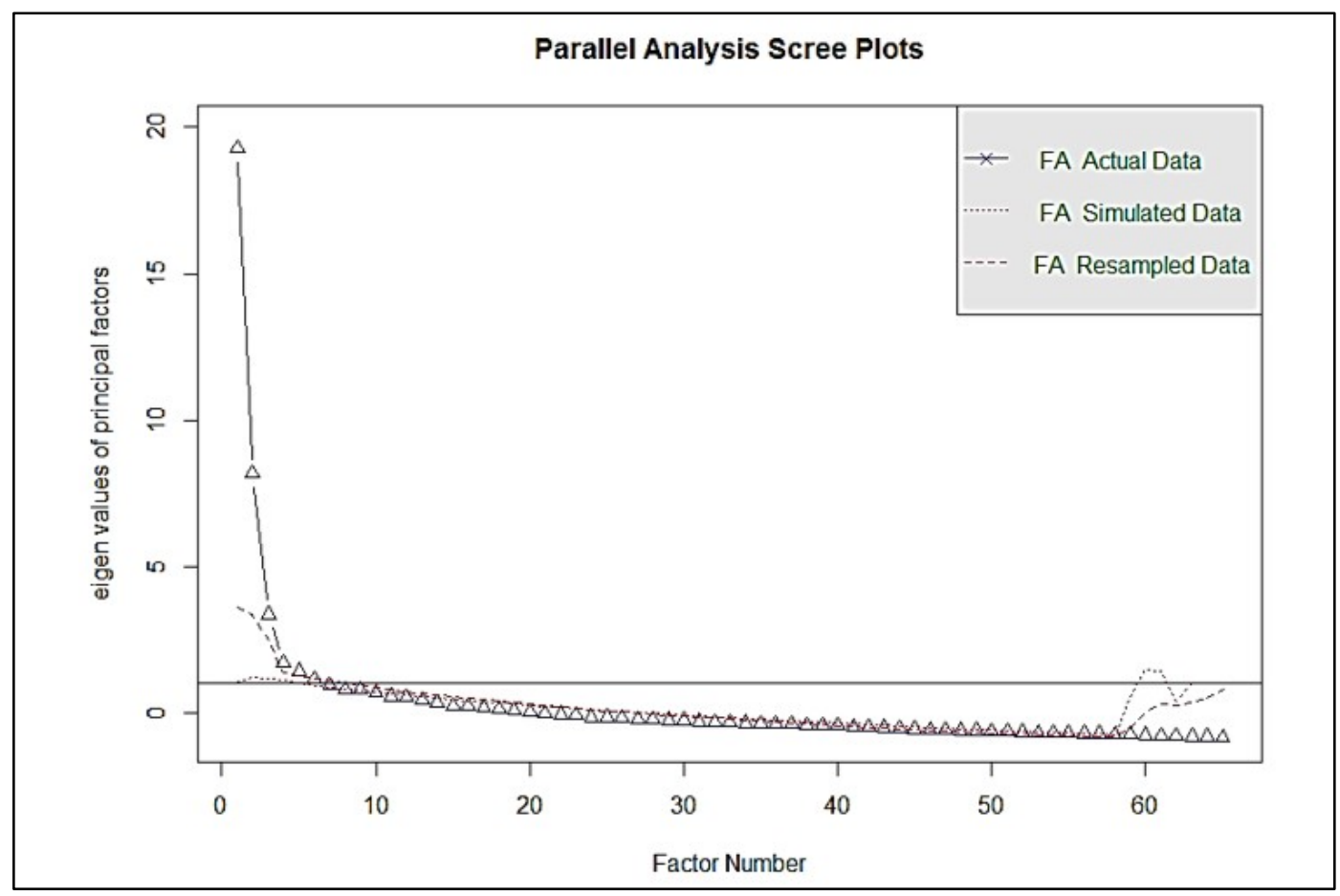

Figure 1. Parallel Analysis Scree Plots for Hearing Impairment of Teachers' Job Satisfaction Scale

Table 1 and figure 1 depict the analysis of the number of factors that underlie the hearing impairment of teachers' job satisfaction scale based on the suggestion of parallel analysis. On the table, column 1 represents the factors of the scale. In all, there are 65 factors (representing the total number of items in the real data and randomly generated test). Column 2 and 3 represent the eigenvalue of the real and randomly generated data respectively. The table shows that there were 6 factors of the real data with an eigenvalue greater than or equal to the eigenvalue of the randomly generated data. Consequently, it was revealed that there are 6 factors that underlie the HITJSS. Also, this suggested the number of factors was further confirmed using parallel analysis scree plots presented in fig.1. However, out of these 6 suggested factors by parallel analysis, only 3 factors were seen to be interpretable after conducting exploratory factor analysis using psych and GPArotation packages implemented in R programming language software. Table 2 presents the three interpretable factors of the scale as follows: 
Arabic Version of Hearing Impairment of Teachers Job Satisfaction:

Validation of Measurement Instrument Using Partial Least Square

Table 2. Interpretable Factors of the Scale

\begin{tabular}{|c|c|c|c|}
\hline Indicators & Factor 1 (School Environment) & Factor 2 (Reward and Personal Growth) & Factor 3 (Classroom Environment) \\
\hline RP1 & & 0.680 & \\
\hline RP2 & & 0.732 & \\
\hline RP3 & & 0.703 & \\
\hline RP4 & & 0.690 & \\
\hline RP5 & & 0.647 & \\
\hline RP6 & & 0.643 & \\
\hline RP7 & & 0.562 & \\
\hline RP8 & & 0.657 & \\
\hline RP9 & & 0.634 & \\
\hline RP10 & & 0.648 & \\
\hline RP11 & & 0.623 & \\
\hline RP12 & & 0.635 & \\
\hline RP13 & & 0.641 & \\
\hline SE14 & 0.734 & & \\
\hline SE15 & 0.594 & & \\
\hline SE16 & 0.687 & & \\
\hline SE17 & 0.565 & & \\
\hline SE18 & 0.647 & & \\
\hline SE19 & 0.581 & & \\
\hline SE20 & 0.394 & & \\
\hline SE21 & 0.673 & & \\
\hline SE22 & 0.629 & & \\
\hline SE23 & 0.509 & & \\
\hline SE24 & 0.645 & & \\
\hline SE25 & 0.607 & & \\
\hline SE26 & 0.517 & & \\
\hline SE27 & 0.624 & & \\
\hline SE28 & 0.541 & & \\
\hline SE29 & 0.402 & & \\
\hline SE30 & 0.442 & & \\
\hline SE31 & 0.377 & & \\
\hline SE32 & 0.539 & & \\
\hline SE33 & 0.578 & & \\
\hline SE34 & 0.458 & & \\
\hline SE35 & 0.613 & & \\
\hline SE36 & 0.574 & & \\
\hline SE37 & 0.695 & & \\
\hline SE38 & 0.576 & & \\
\hline CE39 & & & 0.757 \\
\hline CE40 & & & 0.539 \\
\hline CE41 & & & 0.513 \\
\hline CE42 & & & 0.341 \\
\hline CE43 & & & 0.681 \\
\hline CE44 & & & 0.597 \\
\hline
\end{tabular}


Table 2 continued

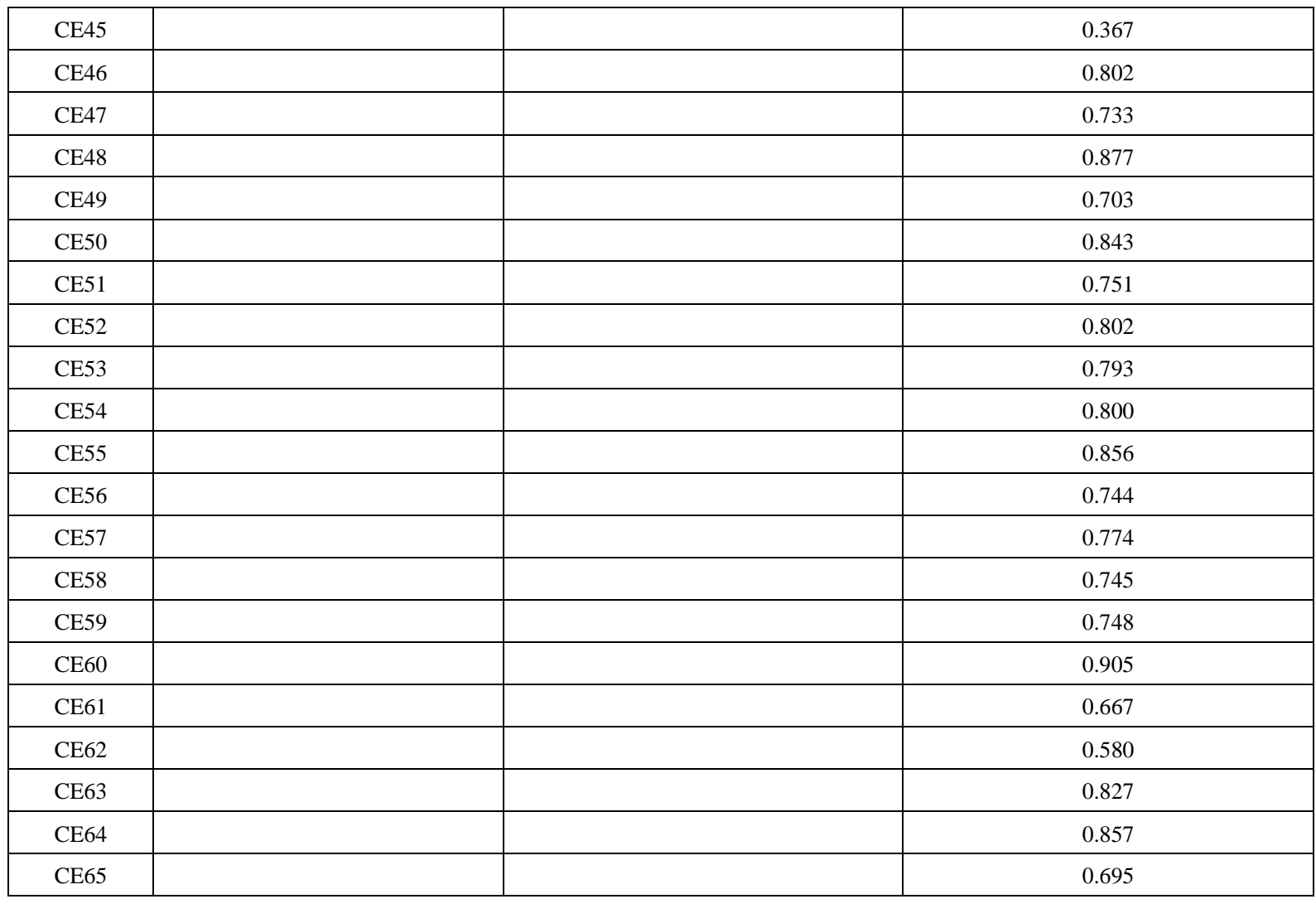

Cursory examination of Table 2 revealed that only three factors underlie the HIJTSS. This was due to the fact that out of the six factors that were identified in table 1, three of the factors had more than three items loaded under them while three factors had less than three items loaded under them. Consequently, the three factors that had less than three items loading were expunged from the rest of other factors. This made three factors be interpretable from the HIJTSS.

\section{(b) What is the convergent and discriminant validity of the scale?}

To answer this question, the measurement model (that is validity and reliability) was conducted using partial least square- structural equation modelling (SEM) implemented in SmartPLS version 3.2.9. SmartPLS is one of the prominent software applications for Partial Least Squares Structural Equation Modeling (PLS-SEM). It was developed by [25]. More importantly, a PLS-SEM assessment can be described in two stages; Stage one dwells on the measurement model or outer model while stage two emphasizes structural model or inner model.
Moreover, stage one can be assessed using reflective and formative model techniques, which have been shown in the literature for evaluating the validity and reliability of any measurement instrument. First, the reflective measures which are represented by arrows pointing from the construct to the indicators are estimated in PLS-SEM by the outer loadings. While the formative measures, which are presented by arrows pointing from the indicator to the construct are calculated by their outer weights. Meanwhile, all indicators in this analysis were reflective measures. Therefore, the assessment of reflective models in this analysis was examined through: indicator reliability, internal consistency reliability and construct validity (convergent and discriminant validity).

\section{Proposed Measurement Model}

The proposed measurement model was presented in Figure 2, which has an independent construct known as hearing impairment of teachers' job satisfaction with sub-constructs such as reward and personal growth, classroom environment and school environment. They are all measured reflectively. 

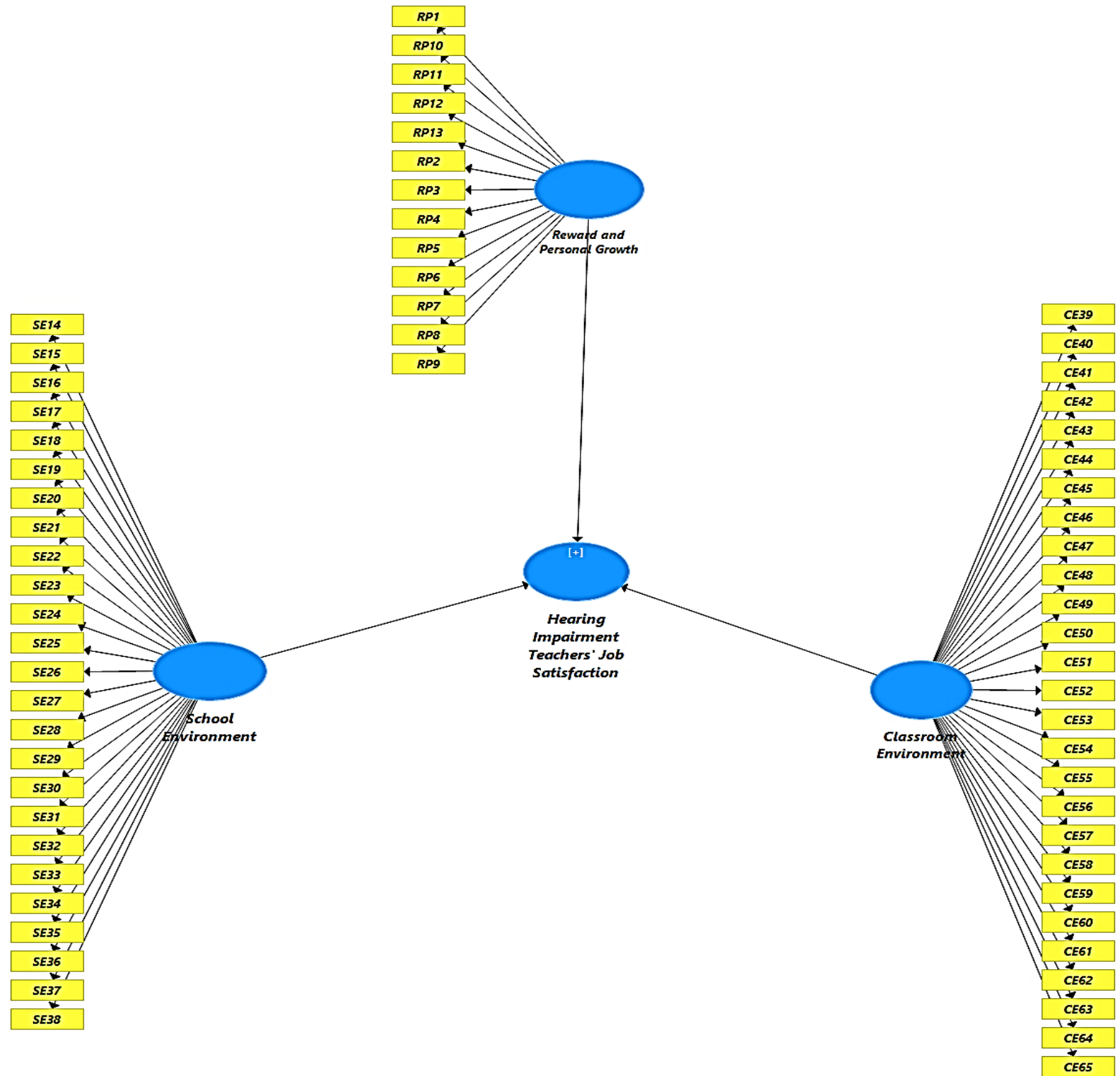

Figure 2. Proposed Measurement Model 


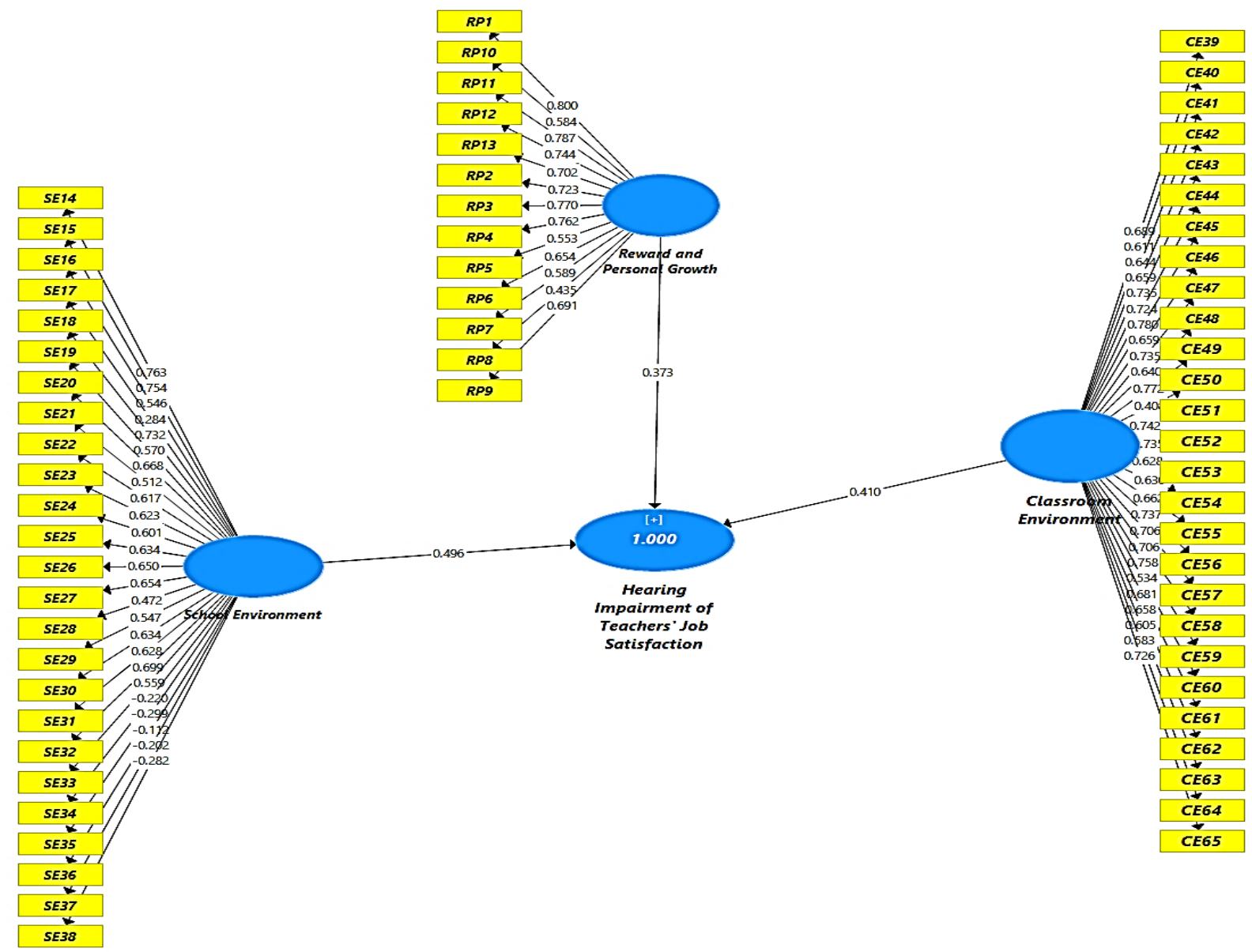

Figure 3. Measurement Model Parameter Estimation ( $\beta$ values)

\section{Assessment of Construct validity (Convergent and discriminant validity)}

To assess the convergent validity of the scales that reflect latent variables, two stages of analysis were conducted: (1) Extraction of the factor loadings of the scales for the determination of the substantial factors and items using factor analysis. (2) PLS-SEM modeling of the measurement model for the assessment of the convergent and discriminant validity assessment. The measurement model consisted of latent variables. The latent variable was multidimensional in nature. As a result of the nature of the latent variable in the model, first order PLS-SEM model was developed. In the first order approach, the sub-factors of the latent variables were model as if they are constructs and their convergent and discriminant validity were assessed. Figure 3 presents the result.

Figure 3 depicts assessment of the construct and its indicators to explain the causalities in the measurement model.

\section{Assessment of convergent validity}

This consisted of three assessment procedures. These include; indicator reliability, composite reliability of each sub-construct and the average variance extracted. [26], suggested that indicator reliability is assessed by their respective factor loading on the underlie construct. [26] also argued that an item is considered reliable, if its factor loading is greater than 0.7 is the standard but loading of 0.4 is acceptable as well. In this study, loading of 0.6 and above was used as cutoff point. Furthermore, a construct is said to be reliable when it returned a value of 0.6 or above reliability coefficient for predictive model. Several measures of reliability exist, for example, Cronbach Alpha, Composite Reliability known as reliability omega, Guttman among others. For this study, the composite reliability was emphasized instead of Cronbach Alpha because Cronbach Alpha tends to underestimate scale reliability. The final criterion of convergent validity, average variance extracted (AVE) is a measure that indicates the amount of variance in an item that is explained by the underlie construct [27]. More importantly, [28] recommended a minimum value of 0.4 for estimated average variance extracted (AVE) to be considered substantial. Table 3 presents the resulting convergent validity of the constructs in the model. 
Arabic Version of Hearing Impairment of Teachers Job Satisfaction:

Validation of Measurement Instrument Using Partial Least Square

Table 3. Reliability and convergent validity of the measurement instrument

\begin{tabular}{|c|c|c|c|c|}
\hline Constructs & Indicators & Outer Loadings & Composite Reliability (CR) & Average Variance Extracted (AVE) \\
\hline \multirow{27}{*}{ Classroom Environment } & CE39 & 0.689 & \multirow{27}{*}{0.957} & \multirow{27}{*}{0.458} \\
\hline & CE40 & 0.611 & & \\
\hline & CE41 & 0.644 & & \\
\hline & CE42 & 0.659 & & \\
\hline & CE43 & 0.735 & & \\
\hline & CE44 & 0.724 & & \\
\hline & CE45 & 0.780 & & \\
\hline & CE46 & 0.659 & & \\
\hline & CE47 & 0.735 & & \\
\hline & CE48 & 0.640 & & \\
\hline & CE49 & 0.772 & & \\
\hline & CE50 & 0.408 & & \\
\hline & CE51 & 0.742 & & \\
\hline & CE52 & 0.735 & & \\
\hline & CE53 & 0.628 & & \\
\hline & CE54 & 0.630 & & \\
\hline & CE55 & 0.662 & & \\
\hline & CE56 & 0.737 & & \\
\hline & CE57 & 0.706 & & \\
\hline & CE58 & 0.706 & & \\
\hline & CE59 & 0.758 & & \\
\hline & CE60 & 0.534 & & \\
\hline & CE61 & 0.681 & & \\
\hline & CE62 & 0.658 & & \\
\hline & CE63 & 0.605 & & \\
\hline & CE64 & 0.583 & & \\
\hline & CE65 & 0.726 & & \\
\hline \multirow{13}{*}{ Reward and Personal Growth } & RP1 & 0.800 & \multirow{13}{*}{0.918} & \multirow{13}{*}{0.469} \\
\hline & RP10 & 0.584 & & \\
\hline & RP11 & 0.787 & & \\
\hline & RP12 & 0.744 & & \\
\hline & RP13 & 0.702 & & \\
\hline & RP2 & 0.723 & & \\
\hline & RP3 & 0.770 & & \\
\hline & RP4 & 0.762 & & \\
\hline & RP5 & 0.553 & & \\
\hline & RP6 & 0.654 & & \\
\hline & RP7 & 0.589 & & \\
\hline & RP8 & 0.435 & & \\
\hline & RP9 & 0.691 & & \\
\hline
\end{tabular}


Table 3 continued

\begin{tabular}{|c|c|c|c|c|}
\hline \multirow{25}{*}{ School Environment } & SE14 & 0.763 & \multirow{25}{*}{0.877} & \multirow{25}{*}{0.315} \\
\hline & SE15 & 0.754 & & \\
\hline & SE16 & 0.546 & & \\
\hline & SE17 & 0.284 & & \\
\hline & SE18 & 0.732 & & \\
\hline & SE19 & 0.570 & & \\
\hline & SE20 & 0.668 & & \\
\hline & SE21 & 0.512 & & \\
\hline & SE22 & 0.617 & & \\
\hline & SE23 & 0.623 & & \\
\hline & SE24 & 0.601 & & \\
\hline & SE25 & 0.634 & & \\
\hline & SE26 & 0.650 & & \\
\hline & SE27 & 0.654 & & \\
\hline & SE28 & 0.472 & & \\
\hline & SE29 & 0.547 & & \\
\hline & SE30 & 0.634 & & \\
\hline & SE31 & 0.628 & & \\
\hline & SE32 & 0.699 & & \\
\hline & SE33 & 0.559 & & \\
\hline & SE34 & -0.220 & & \\
\hline & SE35 & -0.299 & & \\
\hline & SE36 & -0.112 & & \\
\hline & SE37 & -0.202 & & \\
\hline & SE38 & -0.282 & & \\
\hline
\end{tabular}

Table 3 shows convergent validity of the sub-constructs of variables in the model. The table revealed that some items of the constructs in the model had outer loading less than 0.6. The result also revealed that school environment construct in the model detailed AVE less than 0.4. Critical look at Table 3 revealed that the immediate cause of the low level of AVE in the school environment construct could be as a result of low level of outer loadings of some indicators that underlie the constructs. Consequently, items with loading less than 0.6 and negatively loadings were not reliable for the measurement of the constructs they are reflecting. The implication of the result is that the measurement model cannot be tested with such items. The results indicated that some of the items need to be deleted, these include SE16, SE17, SE19, SE21, SE28, SE29, SE33, SE34, SE35, SE36, SE37, SE38, RP5, RP7, RP8, RP10, CE40, CE50, CE60, CE63 and CE64. Once these items were removed, the model displayed better specification for the proposed measurement structure. Figure 4 presents the re-specification of the measurement model. 


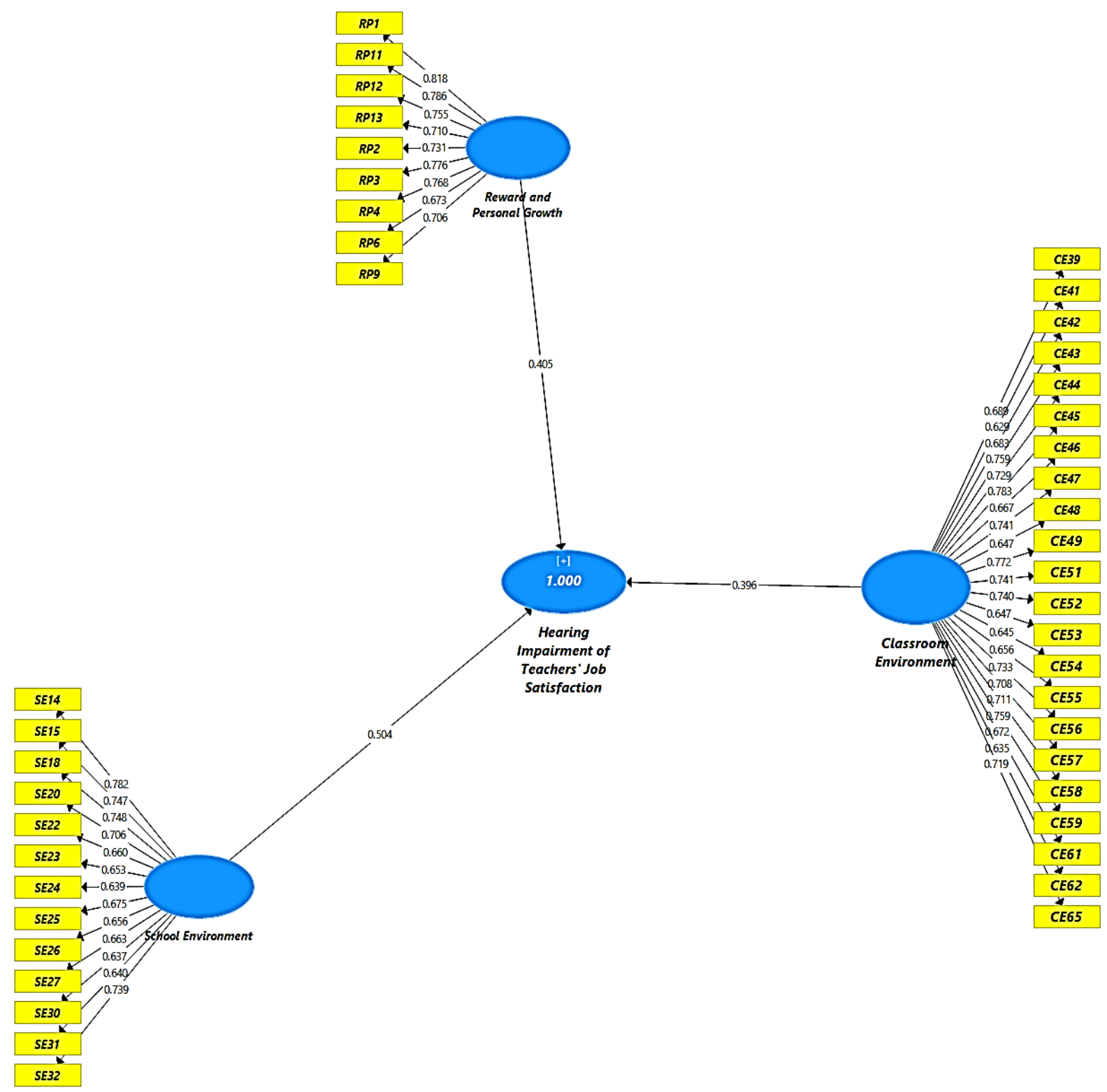

Figure 4. Re-specification of Measurement Model Parameter Estimation ( $\beta$ values)

Figure 4 depicts the analysis of the fitness of the re-specified measurement model to the empirical data. The model shows the assessment of the appropriateness of the constructs and their measures to explain the causalities in the assessment of the measurement model. Tables 5 and
6 present the resulting reliability, convergent and discriminant validity of the constructs in the model and figures 5 and 6 present graphical representation of composite reliability and average variance extracted respectively of the sub-constructs. 
Table 5. Reliability and convergent validity of the measurement instrument

\begin{tabular}{|c|c|c|c|c|}
\hline Constructs & Indicators & Outer Loadings & Composite Reliability (CR) & Average Variance Extracted (AVE) \\
\hline \multirow{22}{*}{ Classroom Environment } & CE39 & 0.689 & \multirow{22}{*}{0.956} & \multirow{22}{*}{0.496} \\
\hline & CE41 & 0.629 & & \\
\hline & CE42 & 0.683 & & \\
\hline & CE43 & 0.759 & & \\
\hline & CE44 & 0.729 & & \\
\hline & CE45 & 0.783 & & \\
\hline & CE46 & 0.667 & & \\
\hline & CE47 & 0.741 & & \\
\hline & CE48 & 0.647 & & \\
\hline & CE49 & 0.772 & & \\
\hline & CE51 & 0.741 & & \\
\hline & CE52 & 0.740 & & \\
\hline & CE53 & 0.647 & & \\
\hline & CE54 & 0.645 & & \\
\hline & CE55 & 0.656 & & \\
\hline & CE56 & 0.733 & & \\
\hline & CE57 & 0.708 & & \\
\hline & CE58 & 0.711 & & \\
\hline & CE59 & 0.759 & & \\
\hline & CE61 & 0.672 & & \\
\hline & CE62 & 0.635 & & \\
\hline & CE65 & 0.719 & & \\
\hline \multirow{9}{*}{ Reward and Personal Growth } & RP1 & 0.818 & \multirow{9}{*}{0.919} & \multirow{9}{*}{0.560} \\
\hline & RP11 & 0.786 & & \\
\hline & RP12 & 0.755 & & \\
\hline & RP13 & 0.710 & & \\
\hline & RP2 & 0.731 & & \\
\hline & RP3 & 0.776 & & \\
\hline & RP4 & 0.768 & & \\
\hline & RP6 & 0.673 & & \\
\hline & RP9 & 0.706 & & \\
\hline \multirow{13}{*}{ School Environment } & SE14 & 0.782 & \multirow{13}{*}{0.921} & \multirow{13}{*}{0.476} \\
\hline & SE15 & 0.747 & & \\
\hline & SE18 & 0.748 & & \\
\hline & SE20 & 0.706 & & \\
\hline & SE22 & 0.660 & & \\
\hline & SE23 & 0.653 & & \\
\hline & SE24 & 0.639 & & \\
\hline & SE25 & 0.675 & & \\
\hline & SE26 & 0.656 & & \\
\hline & SE27 & 0.663 & & \\
\hline & SE30 & 0.637 & & \\
\hline & SE31 & 0.640 & & \\
\hline & SE32 & 0.739 & & \\
\hline
\end{tabular}


Arabic Version of Hearing Impairment of Teachers Job Satisfaction:

Validation of Measurement Instrument Using Partial Least Square

Table 6. HeteroTrait-Mono Trait ratio (HTMT) of the constructs in the model

\begin{tabular}{|c|c|c|c|c|}
\hline Construct & CE & HITJS & RP & SE \\
\hline CE & & & & \\
\hline HITJS & 0.122 & & & \\
\hline RP & 0.147 & 0.744 & & \\
\hline SE & 0.204 & 0.101 & 0.176 & \\
\hline
\end{tabular}

Key: CE = Classroom Environment, RP = Reward and Personal Growth, SE= School Environment, HITJS= Hearing Impairment of Teachers' Job Satisfaction

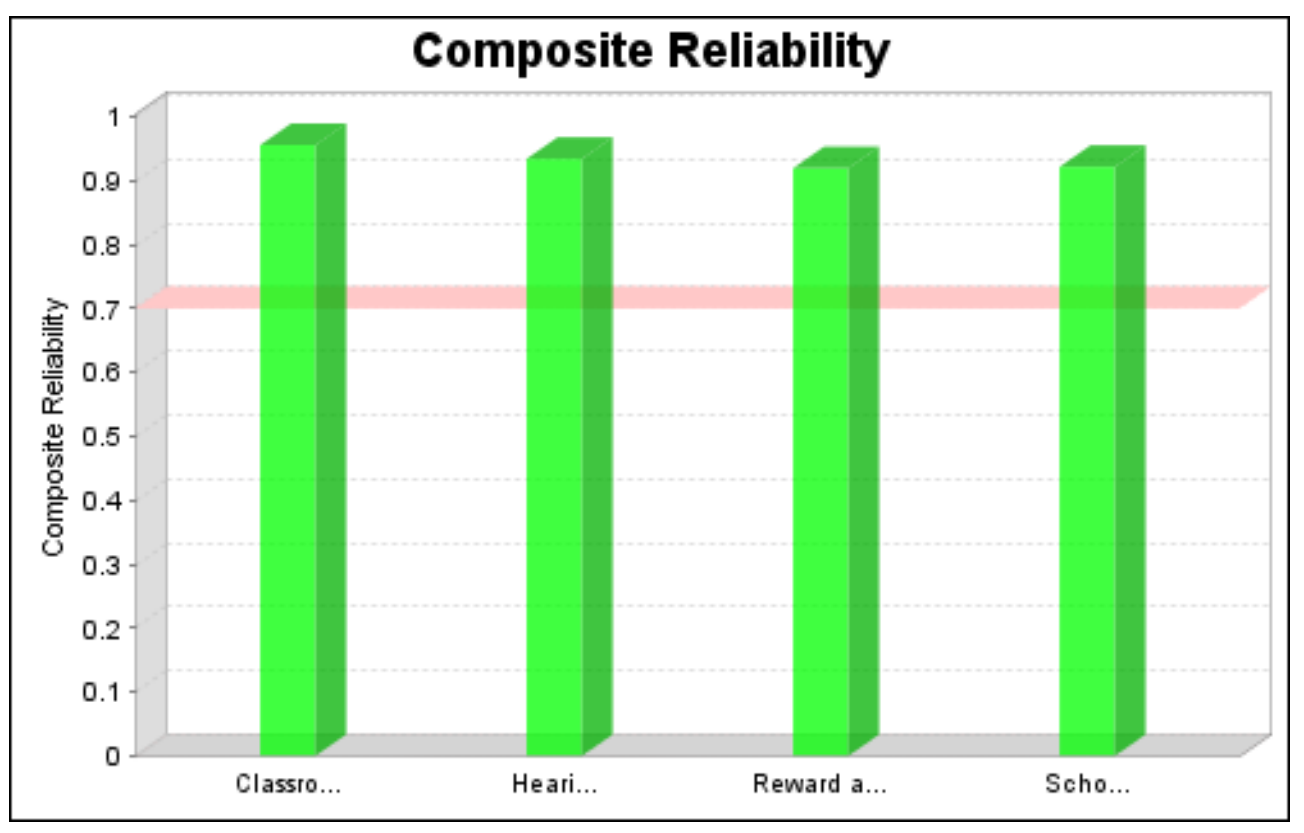

Figure 5. Composite Reliability for the Construct and sub-constructs

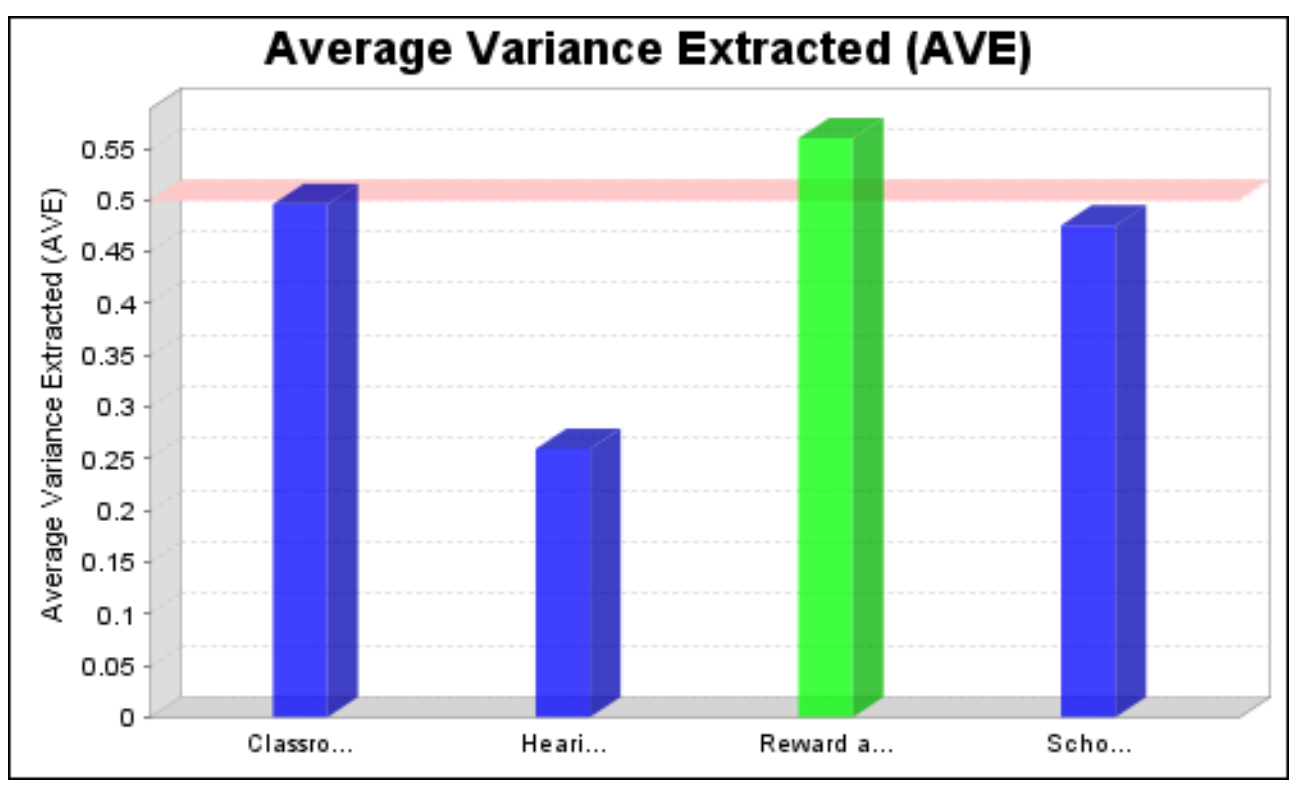

Figure 6. Average Variance Extracted for the Construct and sub-constructs in the Model 
Table 5 shows sub-constructs of the latent variables and their items/measures were reliable (all loading were $\geq 0.6$; all constructs had composite reliability $\geq 0.7)$. The implication of this result is that latent variables in the model were reliable and had convergent validity after the unreliable indicators were expunged.

More importantly, discriminant validity is measured using Fornell-Larcker criterion which states that the square root of AVE must be greater than the correlation of the reflective construct with all other constructs; this criterion is not applicable to formative measurement models and single-item constructs. Checking cross-loadings, all the indicators should load the highest on their associated constructs. Recently, the HeteroTrait-MonoTrait ratio of correlations (HTMT) has become the primary criterion for assessing discriminant validity since it offers superior performance compared with the Fornell-Larcker criterion and the assessment of cross-loadings [29]. Thus, HTMT was emphasized in this study. This was computed for reflective measurement models against the threshold value of 0.90 (that is, for discriminant validity to be established, the HTMT values should not exceed 0.90; [29]. Table 6 presents the assessment of the discriminant validity of the constructs in the model

Table 6 showed that all the values were below the benchmark of HTMT ratio of 0.9. Thus, model's discriminant validity was confirmed. This implies that constructs in the model were distinct from each other. In the overall, the constructs in the model possessed both convergent and discriminant validity.

\section{(c) Do the fit indices explain the model of hearing impairment of teachers' job satisfaction scale?}

To answer this question, confirmatory factor analysis (CFA) implemented in Mplus software version 7.1 was performed to confirm result of factor structure obtained from the measurement model. Figure 7 presents the outline of factor distributions and loading values for the CFA.

Figure 7 depicts result of CFA conducted, with model fit indices $\mathrm{X}^{2}=2020.196, \mathrm{df}=899$ and P-value $=0.310$, $\mathrm{CFI}=0.970, \mathrm{TLI}=0.958, \mathrm{RMSEA}=0.050, \mathrm{SRMR}=$ 0.015, AIC $=27944.582$ and BIC $=28395.798$. Therefore, since the fit indices met the benchmark, it implies that the model fits for the factors are good and reliable. This implies that the measurement model is consistent with observed data. In overall, forty-four items were adjudged to be valid and reliable across the 3 factors, thus make up the measurement instrument for hearing impairment of teachers job satisfaction.

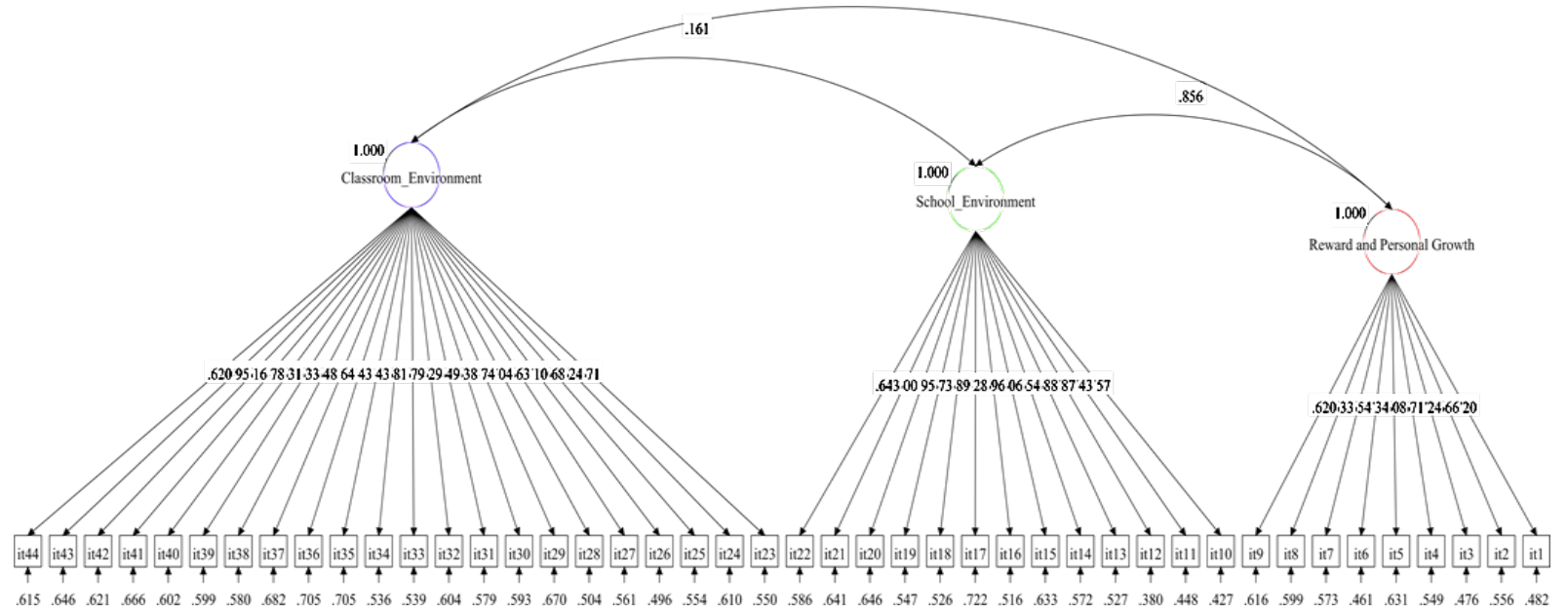

Figure 7. Factor distribution and CFA values 


\section{Conclusions}

The present results show that after establishing psychometric properties of the scale using modern statistical approach, forty-four items survived. Arabic version of the (TJSHIS) valid and reliable for measuring hearing impairment of teachers' job satisfaction. Therefore, the researcher recommends that Arabia countries and similar educational contexts around that region should utilize this instrument to reliably identify their teacher's job satisfaction.

\section{Acknowledgments}

The authors would like to thank the teachers who participated in the study.

\section{Disclosure Statement}

No potential conflict of interest was reported by the author(s).

\section{REFERENCE}

[1] I. Gazzawi, "Job satisfaction Among Information Technology Professional in the US: An Empirical Study,” $J$. Am. Acad. Bus. Cambridge, vol. 13, no. 1, 2008.

[2] A. T. Eğinli, "Çalışanlarda iş doyumu: kamu ve özel sektör çalışanlarının iş doyumuna yönelik bir araştırma." 2009.

[3] T. Oshagbemi, "Personal correlates of job satisfaction: empirical evidence from UK universities,” Int. J. Soc. Econ., vol. 30, no. 12, pp. 1210-1232, 2003.

[4] Abushaira. M., "Job Satisfaction among Special Education Teachers in Jordan,” Int. Interdiscip. J. Educ., vol. 1, no. 3, 2012.

[5] F. M., "The Top 10 Challenges of Special Education Teachers, Special Education,” 2012. [Online]. Available: http://www.friendshipcircle.org/blog/2012/02/01/the-top-10 -challenges-of-special-education-teachers.

[6] Sokanu.org, “'What does a Special Education Teacher do,"” 2017. [Online]. Available: https://www.sokanu.com/careers /special-education-teacher \%0A\%0A.

[7] R. B. F., ““Job satisfaction.”” 2016.

[8] K. Ketheeswaran, "JOB SATISFACTION OF TEACHERS ATTACHED TO THE SPECIAL EDUCATION UNITS," pp. 94-110, 2018, doi: 10.5281/zenodo.1162967.

[9] M. Yavuz, "Examination of the Job Satisfaction of Teachers Working With Individuals in Need of Special Education With Regard to Certain Variables,” vol. 6, no. 7, pp. 73-85, 2018, doi: 10.11114/jets.v6i7.3228.

[10] V. A. A. Jeffrey A. K, “Understanding job satisfaction and its relationship to student academic performance," Middle Sch. J., vol. 44, no. 3, pp. 58-64, 2013.

[11] A. Toropova, E. Myrberg, S. Johansson, and E. Myrberg, "Teacher job satisfaction: the importance of school working conditions and teacher characteristics conditions and teacher characteristics,” Educ. Rev., vol. 00, no. 00, pp. 1-27, 2020, doi: 10.1080/00131911.2019.1705247.

[12] G. R. Hackman, J. R., \& Oldham, Work redesign. Reading, MA: Addison-Wesley, 1980.

[13] C. L. Smith, P. C., Kendall, L. M., \& Hulin, Measurement of satisfaction in work and retirement.. Chicago, IL: Rand McNally.

[14] C. Bascia, N., \& Rottmann, "What's so important about teachers' working conditions? The fatal flaw in North American educational reform,” J. Educ. Policy, vol. 26, no. 6, pp. 787-802, 2011.

[15] M. Liang, G., \& Akiba, “Teachers’ working conditions: A cross-national analysis using the OECD TALIS and PISA data," in International handbook of teacher quality and policy, I. G. K. L. \& M. A. (Eds.), Ed. London: Routledge.

[16] S. Skaalvik, E. M., \& Skaalvik, "Teacher job satisfaction and motivation to leave the teaching profession: Relations with school context, feeling of belonging, and emotional exhaustion,” Teach. Teach. Educ., vol. 27, no. 6, pp. 10291038, 2011.

[17] N. E. Collie, R. J., Shapka, J. D., \& Perry, “School climate and social-emotional learning: Predicting teacher stress, job satisfaction, and teaching efficacy,” J. Educ. Psychol., vol. 104, no. 4, pp. 1189-1211, 2012.

[18] J. T. Spilt, J. L., Koomen, H. M., \& Thijs, "Teacher wellbeing: The importance of teacher-student relationships," Educ. Psychol. Rev., vol. 23, no. 4, pp. 457-477, 2011.

[19] A. Kunter, M., Klusmann, U., Baumert, J., Richter, D., Voss, T., \& Hachfeld, "Professional competence of teachers: Effects on instructional quality and student development," $J$. Educ. Psychol., vol. 105, no. 3, p. 805, 2013.

[20] N. Saleem, F. Aziz, and U. Quraishi, "Morale and Job Satisfaction of University Teachers : A Case from Pakistani Universities,” vol. 41, no. 3, pp. 131-139, 2019.

[21] \& W. G. V. D. Strydom. L, Nortjé. N, Beukes. R, Esterhuyse. K., "JJob satisfaction amongst teachers at special needs schools,"” South African J. Educ., vol. 32, pp. 255-266, 2012.

[22] Luckner, J. L. \& Dorn, B. (2017). Job satisfaction of teachers of students who are deaf or hard of hearing. Journal of Deaf Studies and Deaf Education, 22(3), 336 - 345.

[23] R. B. Kline, "Principles and practice of structural equation modelling, (2nd ed.). New York: The Guilford Press, 2005.

[24] P. Ledesma, R.D. and Valero-Mora, "Determining the Number of Factors to Retain in EFA: an easy-to-use computer program for carrying out Parallel Analysis," $J$. Pract. Assessment, Res. Eval., vol. 12, no. 2, pp. 1-11, 2007.

[25] A. Ringle, C., Wende, S., \& Will, "SmartPLS 2.0 (Beta)." Hamburg, 2005.

[26] M. Hair, J. F., Ringle, C. M., \& Sarstedt, “PLS-SEM: Indeed 
a silver bullet,” J. Mark. Theory Pract., vol. 19, no. 2, pp. 139-151, 2010.

[27] D. F. Fornell, C., \& Larcker, "Evaluating structural equation models with unobservable variables and measurement error," J. Mark. Res., vol. 18, no. 1, pp. 39-50, 1981.

[28] J. A. Hair, J.F., Sarstedt, M., Ringle, C.M. \& Mena, “An assessment of the use of partial least squares structural equation modeling in marketing research,” J. Acad. Mark. Sci., vol. 40, no. 3, pp. 414-433, 2017.
[29] J. Henseler, C. M. Ringle, and M. Sarstedt, “A new criterion for assessing discriminant validity in variance-based structural equation modeling," J. Acad. Mark. Sci., vol. 43, no. 1, pp. 115-135, 2014, doi: 10.1007/s11747-014-0403-8.

[30] J. Satisfaction et al., “would you describe yourself :," pp. 35.

[31] Sekaran, U. (2003) Research Methods for Business: A Skill-Building Approach. 4th Edition, John Wiley \& Sons, New York. 